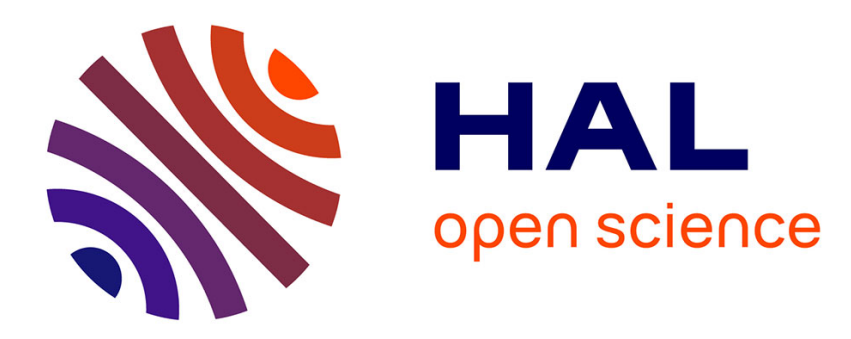

\title{
Mergers, cartels and leniency programs: the role of production capacities
}

\author{
Emilie Dargaud
}

\section{To cite this version:}

Emilie Dargaud. Mergers, cartels and leniency programs: the role of production capacities. 2008. halshs-00303671

\section{HAL Id: halshs-00303671 \\ https://shs.hal.science/halshs-00303671}

Submitted on 22 Jul 2008

HAL is a multi-disciplinary open access archive for the deposit and dissemination of scientific research documents, whether they are published or not. The documents may come from teaching and research institutions in France or abroad, or from public or private research centers.
L'archive ouverte pluridisciplinaire HAL, est destinée au dépôt et à la diffusion de documents scientifiques de niveau recherche, publiés ou non, émanant des établissements d'enseignement et de recherche français ou étrangers, des laboratoires publics ou privés. 


\title{
DOCUMENTS DE TRAVAIL - WORKING PAPERS
}

\author{
W.P. 08-14
}

Mergers, cartels and leniency programs : the role of production capacities

\section{Emilie Dargaud}

Mai 2008

GATE Groupe d'Analyse et de Théorie Économique UMR 5824 du CNRS

93 chemin des Mouilles - 69130 Écully - France

B.P. 167 - 69131 Écully Cedex

Tél. +33 (0)4 72866060 - Fax +33 (0)4 72866090

Messagerie électronique gate@gate.cnrs.fr

Serveur Web : www.gate.cnrs.fr 


\title{
Mergers, cartels and leniency programs : the role of production capacities*
}

\author{
DARGAUD Emilie ${ }^{\dagger}$ \\ GATE $^{\ddagger}$ \\ University of Lyon - ENS-LSH Lyon and Centre Léon Berard
}

May 2008

\begin{abstract}
In this paper, we study the impact of a merger on collusion depending on the endowment of capital asset among firms. We show that the merger makes the collusion easier to sustain when asymmetric capital stock combines with less efficient insiders because of more symmetric conditions and closer incentive constraints. Moreover, this model allows us to determine an optimal threshold of asymmetry among insiders and outsiders such as a merger has pro-competitive effects and we compare this value with the value which would restore perfect symmetry between firms after the merger.

Keywords: Mergers, Collusion, Leniency Programs.

JEL classification: L11; L41; K42
\end{abstract}

*I thank David Balan, Laurent Flochel, Michele Polo, Ashley Roughton, Saïd Souam, Bruno Versaevel for valuable comments. Of course any errors remain my own.

${ }^{\dagger}$ Tel.: +33(0)472866112 ; fax: +33(0)472866090 ; e-mail: dargaud@gate.cnrs.fr

${ }^{\ddagger}$ Groupe d'Analyse et de Théorie Economique, UMR 5824 du CNRS -93, chemin des mouilles, 69130 Ecully- France 


\section{Introduction}

Merger control is a preventive authorization system with the major goal to prevent mergers which diminish competitiveness. The antitrust authority analyses if a merger can make it more likely or more effective for firms to coordinate their actions (coordinated effects) and if it can make it profitable for the merging firms to reduce output and raise price unilaterally (unilateral effects) ${ }^{1}$.

The impact of a merger on the possibility to collude ex post is studied by several authors ${ }^{2}$ who show that if the asymmetry between firms is increased after a merger, then the risk of coordinated actions decreases. When firms become very asymmetric, then it is more difficult to provide the right incentives to small firms not to deviate from the collusive path.

From the merger control point of view, our model reinforces these results and completes the existing literature to determine a threshold of asymmetry necessary for a merger to have pro-competitive effects.

Another strand of literature related to this paper deals with leniency programs (as Motta-Polo, 2003). These programs reduce fines for cartel members who report themselves to and assist the antitrust authority, and the impact of leniency programs can be seen in the recent increase in successful cartel investigations. For example, in the period from 14 February 2002 until the end of 2005, the European Commission received 167 applications under the 2002 Leniency Notice. Of these applications, 87 were requests for immunity and 80 were requests for reduction in fines. The Commission has granted 51 decisions for conditional immunity. Over the same period,

\footnotetext{
${ }^{1}$ Council Regulation (EC) no 139/2004

${ }^{2}$ Compte, Jenny and Rey (2002), McAfee and Williams (1992), Vasconcelos (2005)
} 
the Commission rejected or decided not to deal any further with 23 applications and had under scrutiny 13 more recent applications. ${ }^{3}$. The presence of leniency programs introduces a coordination game between the cartel members (apply for leniency or not?). Motta and Polo (2003) show that leniency programs have two possible effects. The first is the deviation from the cartel agreement by firms which report information to the antitrust authority. The second (being a negative effect) is the attenuation of the expected cost of anticompetitive behavior because of reduced fines. One key mechanism in their model is the possibility for firms to apply for leniency even if the investigation is opened.

Our model combines two streams of the literature. Firstly, from the point of view of merger control (ex ante system), we study the impact of a merger on collusion and estimate a threshold of asymmetry between firms. Secondly, we take into account leniency programs to detect and punish collusive agreements (ex post system). Taking these two streams into account allows us to develop a global model and to obtain clear policy implications.

Our principal results are as follows.

We show that when the endowment of capital asset is symmetric initially, then collusion is less feasible after the merger takes place. Indeed, the merger leads asymmetry among firms, and this determines different incentives to collude. Harder conditions for collusion arise for the same argument also when firms' capital stocks are asymmetric pre-merger and the insiders are more efficient. Ex post, the outsiders are smaller and weaker, which make their incentives harder to meet. But when asymmetric capital stock combines with less efficient insiders, then the merger makes the collusion easier to sustain

\footnotetext{
${ }^{3}$ European Commission, MEMO/06/357.
} 
because of more symmetric conditions and closer incentive constraints. This model allows us to determine an optimal threshold of asymmetry among insiders and outsiders such as a merger has pro-competitive effects. This threshold only depends on the number of active firms in the industry and on the amount of fine but does not depend on the discount factor. Finally, we compare this value with the value which would restore perfect symmetry between firms after the merger takes place.

The paper is organized as follows. In section 2 we describe the basic model. Characterizations of equilibria are provided in section 3. In sections 4 and 5, we deal with the impact of a merger on collusion. Concluding remarks follow in section 6 . Proofs of results appear in the appendix.

\section{The model}

We consider a simple framework consisting of a Cournot homogeneous product industry, with $n$ firms, $n \geq 4^{4}$. Demand is linear, with price $p=1-Q$, where $Q$ denotes the total quantity produced in the industry. Following Perry and Porter (1985), cost is assumed to be dependant on the capital owned by the firms :

$$
C\left(q_{i}, k_{i}\right)=c q_{i}+\frac{q_{i}^{2}}{2 k_{i}}, \forall i \in[1, n]
$$

with $0 \leq c<1$ and $q_{i}$ denotes the quantity chosen by firm $i$. Each firm has a share of a specific asset that affects marginal costs, which is its production capacity, denoted by $k_{i}$. The total supply of capital in the industry is assumed to be fixed, which is normalized to one: $\sum_{i=1}^{n} k_{i}=1, \forall i=1 \ldots n$.

We assume an upward-sloping linear marginal cost function, where the

\footnotetext{
${ }^{4}$ The minimal number of firms $(n=4)$ is made clear in the appendix A.
} 
slope is a decreasing function of the firms' share of the industry's stock of capital :

$$
\frac{\partial C\left(q_{i}, k_{i}\right)}{\partial q_{i}}=c+\frac{q_{i}}{k_{i}}>0 ; \quad \frac{\partial^{2} C\left(q_{i}, k_{i}\right)}{\partial q_{i}^{2}}>0 ; \quad \frac{\partial^{2} C\left(q_{i}, k_{i}\right)}{\partial q_{i} \partial k_{i}}<0
$$

In this context, a firm is more efficiency if it is "large" (if it owns a large fraction of the capital stock).

In a first part, we suppose that firms are ex ante symmetric : $k_{i}=$ $k_{j}, \forall i, j \in[1, n]$. In a second part, we loosen this assumption by considering two groups of firms with different production capacities. More precisely, two identical firms (firms which are supposed to merge) are to have the same production capacity, denoted by $k_{1}=k_{2}$, which is different from the production capacity of the other firms (the outsiders), denoted by: $k_{j}(\forall j \neq$ $1,2)$.

We consider a merger between the two firms 1 and 2 and we study its impact on the risk of collusion. The outcome of the execution of a collusive agreement is assumed to be that the colluding firms will thence reduce output below the competitive level. We suppose that the antitrust authorities use leniency programs; these programs provide the incentive of reduced fines to firms which reveal information about collusion to the antitrust authorities.

Motta-Polo (2003) design four parameters for the enforcement policy:

- $F \in[0, \bar{F}]$ : the value of the fine if firms are detected by the antitrust authority and have not cooperated with it, $\bar{F}$ being the maximum possible fine which can be imposed.

- $f \in[0, F]$ : the value of the reduced fine for the firm which denounces the collusive agreement. It is assumed that all firms which cooperate with the antitrust authority will be granted the same reduced fines. 
It is also assumed that the reduction is high enough in order for the leniency program to be really effective (if $f$ is close to the full fine $(F)$, firms will not have incentive to reveal information).

- $\alpha \in[0,1]$ : the probability that firms are reviewed by the antitrust authority.

- $s \in[0,1]$ : the probability that the antitrust authority successfully concludes the investigation when firms do not cooperate.

These parameters are assumed to be exogenous.

Type I errors (firms not colluding are still prosecuted) are assumed not to happen whereas Type II errors (colluding firms not fined) are assumed to happen.

The timing of the game is as follows (with $n$ or $n-1$ active firms): At $t=1$, firms decide to reach a collusive agreement or to deviate (playing non cooperatively). The collusion strategy is modelled on the basis of a trigger strategy: once a firm deviates from the collusive agreement, all the firms will play non cooperatively until the end of the game ${ }^{5}$.

If no firm deviates until a time $t$ then they collude again and get a profit $\pi_{M}$. We study the case in which firms can sustain the joint profit maximization, so the subscript $M$ indicates a collusive outcome since collusion aims at monopolizing the industry. If, at time $t$, the antitrust authority decides to open an investigation then there are two assumed outcomes:

- Cooperation: firms denounce the cartel to the antitrust authority; they pay the reduced fine $f$, play non cooperatively during one period and

\footnotetext{
${ }^{5}$ These strategies have been initially suggested by Friedman (1971)
} 
restart collusion after an inquiry is concluded. If however a firm deviates from the collusive agreement, firms play non cooperatively until the end of the game.

- No cooperation: at $t+1$ (firms do not cooperate with the antitrust authority so one other period is needed to conclude the investigation), if firms are not condemned with probability $(1-s)$ then they continue to play cooperatively; if they are found guilty, then they pay the total fine $F$ and have to play non cooperatively during one period. As in the cooperation case, in one firm deviates from the collusive agreement, firms play non cooperatively until the end of the game.

Consequently, in this game, there are two types of deviation : the deviation from the collusive agreement and the reporting to the antitrust authority.

The equilibria of the game can now be analysed.

\section{Equilibria}

This section describes all the various types of equilibria. We describe the perfect Nash equilibria of the game and we have to resolve this game considering merger or not in the first period (game with $n$ or $n-1$ active firms).

Firstly, we consider the case of symmetric firms. In this context, Motta and Polo (2003) suggest that there are three types of equilibria: no collusion $(\mathrm{NC})$, collusion and revelation (CR) and collusion and no revelation (CNR). The existence of these equilibria depends on the value of the relevant parameters. CR equilibrium exists if the profit of firm colluding and revealing to the antitrust authority is greater than the profit of a firm which deviates. 
CNR equilibrium exists if firm which colludes and does not reveal information has no incentive to reveal information to the antitrust authority and also to deviate from the collusive agreement.

Let $\delta \in(0,1)$ be the common discount factor.

The results obtained by Motta-Polo (2003) are as follows:

lemma 1. (Motta-Polo (2003) for low values of $f)^{6}$

- for $s \in\left[0, s_{C N R}\left[\right.\right.$ and $\alpha<\alpha_{N C}(s): C N R$ and $C R$ exist and $C N R$ is Pareto dominant.

- for $s \in\left[s_{C N R}, 1\right]$ and $\alpha \in\left[0, \alpha_{C R}[: C N R\right.$ and $C R$ exist and $C R$ is Pareto dominant.

- in other cases: only NC equilibrium exists.

with:

$$
\left\{\begin{aligned}
s_{C N R} & =\frac{(1+\delta)\left(\pi_{M}-\pi_{N}+f\right)}{\delta\left(\pi_{M}-\pi_{N}+F\right)} \\
\alpha_{C R} & =\frac{\pi_{M}-(1-\delta) \pi_{D}-\delta \pi_{N}}{\left(\pi_{M}-\pi_{N}+f\right)} \\
\alpha_{N C} & =\frac{(1+\delta)\left(\pi_{M}-(1-\delta) \pi_{D}-\delta \pi_{N}\right)}{\delta s\left(\pi_{M}-\pi_{N}+F\right)}
\end{aligned}\right.
$$

The following graphic represents the Subgame Perfect Equilibria. ${ }^{7}$

\footnotetext{
${ }^{6}$ Motta and Polo (2003) consider three low values for the reduced fine. We study the case in which the leniency program is the most effective, consequently: $f<\delta\left(\pi_{D}-\pi_{N}\right)$

${ }^{7}$ When several equilibria can exist, we keep only the Pareto dominant
} 


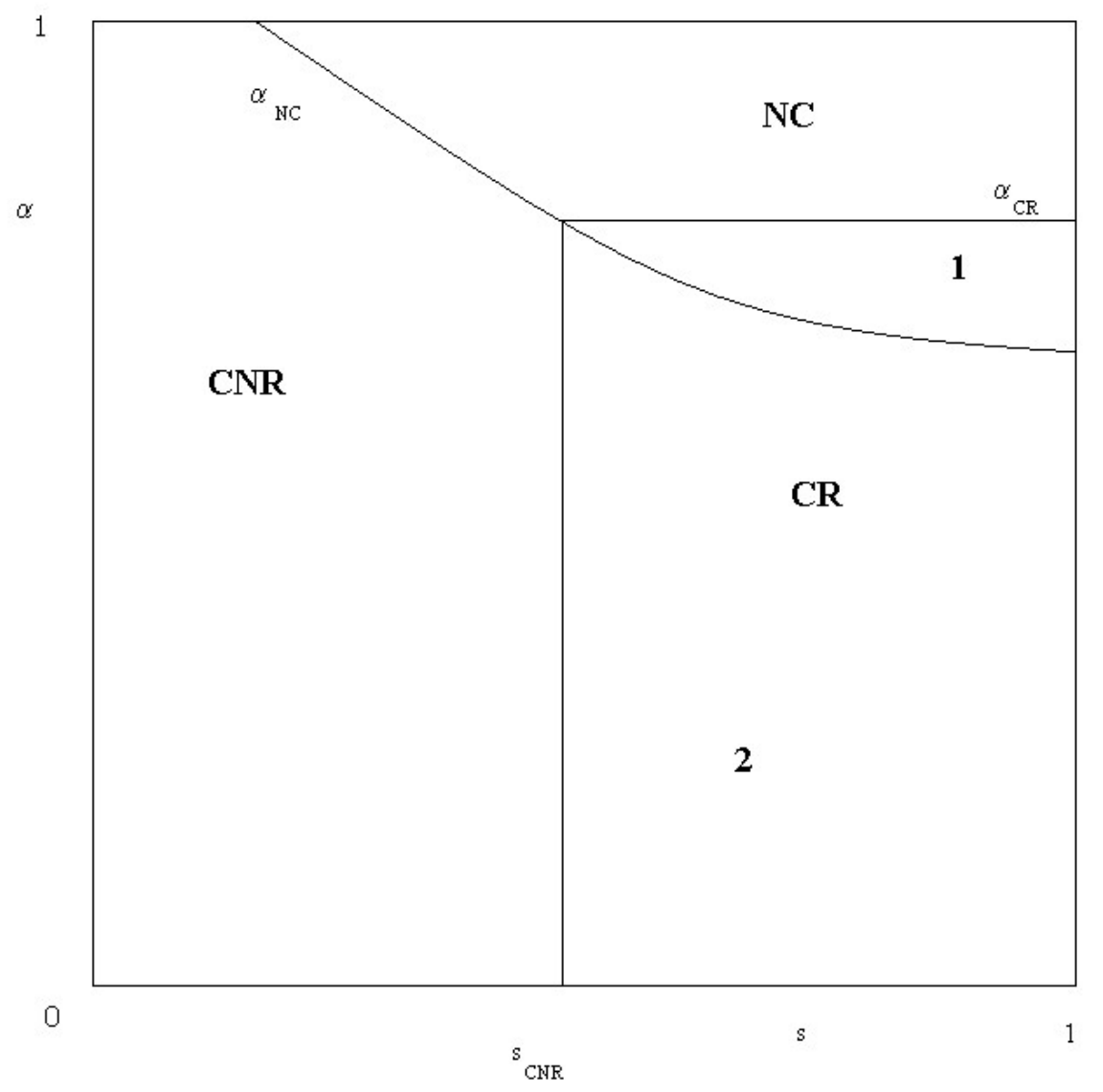

Figure 1: Subgame Perfect Equilibria

The region labelled 1 represents the area where firms make collusive agreements under leniency programs whereas they would not collude in the absence of any leniency program. Region 2 represents the area where the parameters are such as to make ex post desistence easier by encouraging revelation and by shortening investigations time.

In order for $\alpha_{C R}$ to be strictly positive, it is necessary that $\delta$ must be higher than $\tilde{\delta}=\frac{\pi_{D}-\pi_{M}}{\pi_{D}-\pi_{N}}$. $\tilde{\delta}$ is the usual critical discount factor when firms collude with no threat of prosecution. The case $\alpha_{C R}<0$ means that firms 
never make any collusive agreement.

\section{The impact of a merger on collusion}

The two firms which propose to merge are identical $\left(k_{1}=k_{2}\right)$. The others have another same production capacity : $k_{i}=k_{j}, \forall(i, j) \in n,(i, j) \neq(1,2)$.

The impact of a merger on collusion is captured in our framework by comparative statics analysis on each border line of the Figure 1. In this section, we present the method and the results for the border line $\alpha_{C R}$. In the next section, the two other border lines are studied.

To obtain comparative statics results on $\alpha_{C R}$, we compute the value of $\phi=\alpha_{C R}^{b m}-\alpha_{C R}^{a m}$, where the superscripts $b m$ and am denote the threshold value $\alpha_{C R}$ before and respectively after the merger. If $\phi$ is strictly positive, then the border line $\alpha_{C R}$ in the Figure 1 moves down and so, there exist some values of $\alpha$ and $s$ for which firms collude and reveal before merger whereas they do not collude if the merger is accepted by the antitrust authority. In other words, a merger attenuates the scope of collusion.

To simplify the calculation, we assume that $c=0$.

Individual profit functions of the firms $(\forall i=1 \ldots n)$ are given by :

$$
\left\{\begin{array}{l}
\pi_{M}=\frac{1}{6} k_{i} \\
\pi_{D}=\frac{k_{i}\left(-2-k_{i}\right)^{2}}{18\left(1+2 k_{i}\right)} \\
\pi_{N}=\frac{\beta_{i}\left(2 k_{i}-\beta_{i}\right)}{2 k_{i}(1+\beta)^{2}}
\end{array}\right.
$$

with $\beta_{i}=\frac{k_{i}}{k_{i}+1}$ and $\beta=\sum_{i=1}^{n} \beta_{i}$.

Proof. See appendix B.

As regards collusion profit, we study perfect collusion in the sense that all firms make a collusive agreement and we suppose that monopoly aggregate 
output is simply divided in proportion to capital endowments. This is a key element in the model. Concerning deviation profit, we suppose that deviation takes the form which is conventionally assumed in this type of models: the deviant takes the allocated cartel outputs of all other firms as given and selects the output which maximizes its own profits.

The previous expressions of profits are calculated assuming that $n$ firms are active (no merger situation). We do the same for the other case, where $n-1$ firms stay active. In this case, the production capacity of merged entity is equal to: $k_{m}=k_{1}+k_{2}=2 k_{1}$.

\section{The case of ex ante symmetric firms}

We suppose that : $k_{i}=k_{j}, \forall i \neq j, \forall(i, j) \in[1, n]$. We have to compute the value of $\alpha_{C R}$ before merger (which is the same for insider or outsider because we consider ex ante symmetric firms).

We consider an effective leniency program and a high reduction of fine in case of revelation of information. The reduced fine must satisfy the following inequality:

$$
f<\delta\left(\pi_{D}-\pi_{N}\right)
$$

We choose to apply the total immunity for firms which reveal the information to the antitrust authority $(f=0)$, because it is optimal from the authority point of view ${ }^{8}$.

We compute the difference: $\alpha_{C R}^{b m}-\alpha_{C R}^{a m}$ for the insiders and the outsiders and we obtain:

\section{lemma 2.}

- For the insiders: $\alpha_{C R}^{b m}<\alpha_{C R}^{a m}, \forall n$

\footnotetext{
${ }^{8}$ See Motta and Polo (2003).
} 
- For the outsiders: $\alpha_{C R}^{b m}>\alpha_{C R}^{a m}, \forall n$

Proof. See appendix C.

After merger, the border line $\alpha_{C R}$ moves up for the insiders and moves down for the outsider firms.

The most restricting border line $\alpha_{C R}$ is the one which is, graphically, the lowest down (because we consider perfect collusion in the industry, if only one firm has no incentive to make a collusive agreement, the $\mathrm{NC}$ equilibrium takes place). It is given by:

$$
\min _{i=\text { ins }, \text { out }} \alpha_{C R}^{i}
$$

where $i$ designs insiders or outsiders.

We obtain the following proposition:

proposition 1. If each firm has initially the same production capacity, then a merger will increase (resp. decrease) the space of parameters under which firms tend to collude for the insiders (resp. the outsiders). The merger will then reduce the space of parameters under which firms tend to make perfect collusion in the industry.

The following graphic summarizes the previous results: 


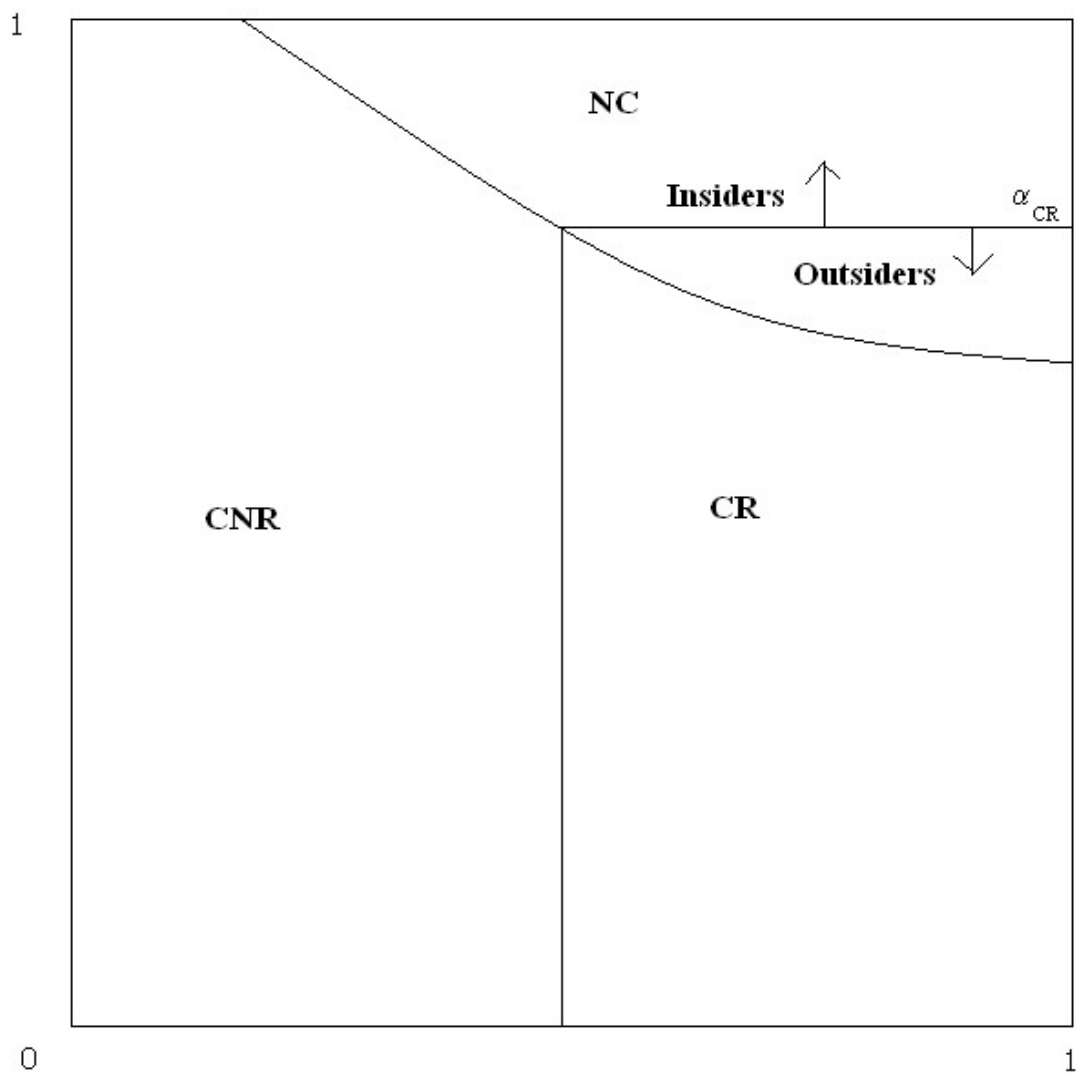

Figure 2: The impact of a merger on $\alpha_{C R}$ in the symmetric case.

Post-merger firms are asymmetric, this decreases the possibility to make collusive agreements because outsiders have incentives to deviate from the collusive agreement. In fact, outsiders have smaller production capacity than merged entity, which creates relative inefficiency. Recall that the collusive profit is computed with a key element of the model which is that monopoly aggregate output is divided in proportion to capital endowments, and so asymmetry causes incentives to deviate form this collusive agreement. This result reinforces the results obtained by Cabral (2000), Rothschild (1999) or Penard (1997) who show that it is easier for firms to make collusive agree- 
ments when they are symmetric.

\section{The case of ex ante asymmetric firms}

In this section, we suppose that, initially, the insiders have the same production capacity $\left(k_{1}=k_{2}\right)$, the outsiders have another same production capacity too $\left(k_{i}=k_{j}, \forall(i, j) \neq(1,2)\right)$, which is different from the production capacity of the insiders $\left(k_{i} \neq k_{1}, \forall i \neq(1,2)\right)$.

We design by $\Delta$ the parameter measuring the ex ante relative asymmetry of firms. More precisely, we suppose that the production capacity of a merging firm is:

$$
k_{1}=k_{2}=\frac{1+\Delta}{n}
$$

The production capacity of an outsider is then ${ }^{9}$ :

$$
k_{j}=\frac{1-\left(\frac{2 \Delta}{n-2}\right)}{n}, \forall j \neq(1,2)
$$

We have to analyse two cases. Whether we consider an ex ante relative efficiency of insiders: $\Delta>0$, or an ex ante relative efficiency of outsiders: $\Delta<0$.

For the first case:

$$
\Delta \in] 0, \frac{n}{2}-1[
$$

For the second case:

$$
\Delta \in]-1,0[
$$

Proof. See appendix D.

\footnotetext{
${ }^{9}$ The total production capacity in the industry is equal to 1 , so : $2 k_{1}+(n-2) k_{j}=1$, $\forall j \neq(1,2)$. Then we check that : $2\left(\frac{1+\Delta}{n}\right)+(n-2)\left(\frac{1-\left(\frac{2 \Delta}{n-2}\right)}{n}\right)=1$.
} 
We compute the value of $\phi\left(\alpha_{C R}^{b m}-\alpha_{C R}^{a m}\right)$ for each category of firms and we obtain the following lemma:

\section{lemma 3.}

- For the insiders : $\left.\alpha_{C R}^{b m}<\alpha_{C R}^{a m}, \forall n, \forall \Delta \in\right]-1, \frac{n}{2}-1[$

- For the outsiders : $\left.\alpha_{C R}^{b m}>\alpha_{C R}^{a m}, \forall n, \forall \Delta \in\right]-1, \frac{n}{2}-1[$

Proof. See appendix E.

Whatever the sign of $\Delta$ is, a merger between firms 1 and 2 will reduce at one and the same time the space of no collusion for insiders and the space of collusion for outsiders. We have to determine the total effect of the merger.

Firstly, we compare the border line $\alpha_{C R}$ before merger for each category of firms. We design by $\alpha_{C R}(O u t)$ the border line for outsider firms, and by $\alpha_{C R}($ Ins $)$ the border line for insiders. Lemma 4 follows:

\section{lemma 4.}

$$
\alpha_{C R}^{b m}(\text { Out }) \leq \alpha_{C R}^{b m}(\text { Ins }) \Leftrightarrow \Delta \geq 0
$$

To prove this, we do exactly the same than for the lemma 3.

When there is a relative efficiency which favours insiders $(\Delta>0)$, we obtain the following result:

$$
\alpha_{C R}^{a m}(\text { Ins })>\alpha_{C R}^{b m}(\text { Ins })>\alpha_{C R}^{b m}(\text { Out })>\alpha_{C R}^{a m}(\text { Out })
$$

When the asymmetry favours insiders, outsiders have higher incentives to deviate from a collusive agreement because the merger reinforces the relative inefficiency. For the insiders, the merger reinforces their relative efficiency and increases the space of parameters under which firms tend to collude. 
We then obtain the following result:

$$
\min _{i=\text { ins,out }} \alpha_{C R}^{a m}<\min _{i=\text { ins,out }} \alpha_{C R}^{b m}
$$

Consequently, the merger reduces the space of collusion and revelation for firms because outsiders have incentives to deviate from the collusive agreement. Proposition 2 follows:

proposition 2. When the ex ante asymmetry favours insiders, then the space of parameters under which firms make a collusive agreement is reduced after the merger.

The following graphic summarizes our results when we consider an ex ante asymmetry favouring insiders (we represent only the area which is interesting for us, which is the North-East of the Figure 1). 


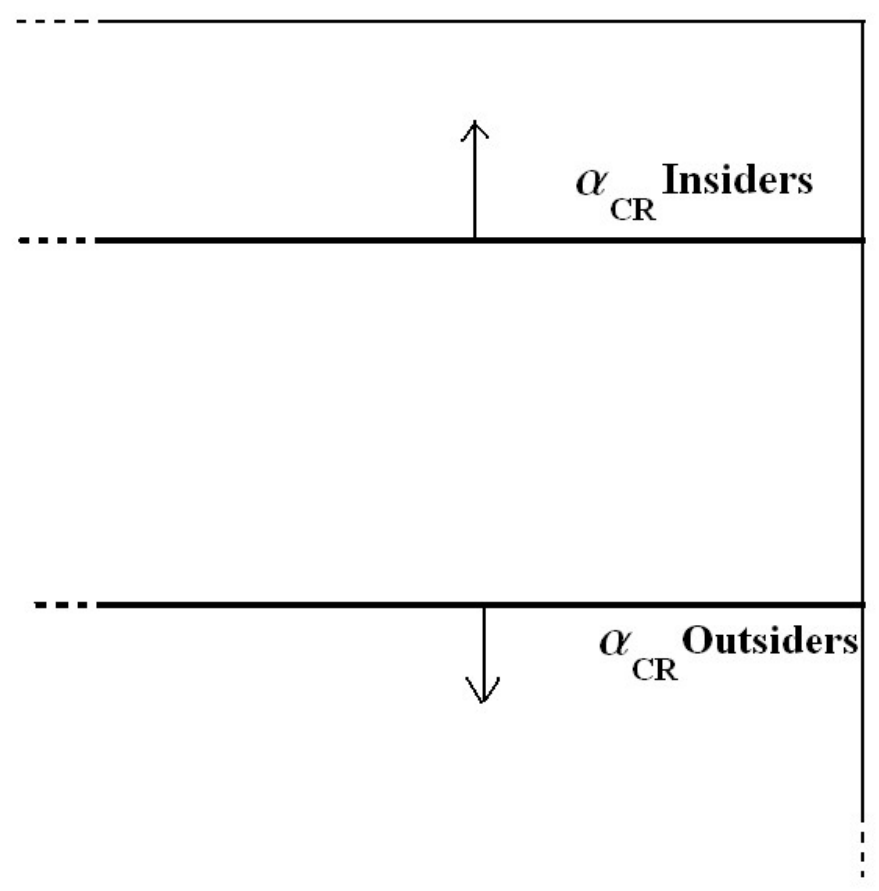

$\Delta>\mathbf{0}$

Figure 3: The impact of a merger on $\alpha_{C R}$ in the case: $\Delta>0$.

We now look into the case in which there is an ex ante relative inefficiency of insiders $(\Delta<0)$. We know that the space of collusion under outsiders tend to collude decreases after the merger, whereas it increases for insiders ${ }^{10}$. Moreover, before merger, $\alpha_{C R}$ for outsiders is above $\alpha_{C R}$ for insiders ${ }^{11}$. In order to evaluate the global impact of the merger, we have to compare $\alpha_{C R}$ for insiders before merger with $\alpha_{C R}$ for outsiders after merger. We obtain the following lemma.

lemma 5. $\alpha_{C R}^{b m}($ Ins $)>\alpha_{C R}^{a m}($ Out $)$ for $\Delta>\tilde{\Delta}(n)$.

\footnotetext{
${ }^{10}$ See lemma 3.

${ }^{11}$ See lemma 4.
} 
Proof. Values of $\tilde{\Delta}(n)$ are reported in the appendix F.

We then obtain the following results:

- if $\Delta>\tilde{\Delta}(n):\left\{\alpha_{C R}^{a m}(\right.$ Ins $), \alpha_{C R}^{b m}($ Out $\left.)\right\}>\alpha_{C R}^{b m}($ Ins $)>\alpha_{C R}^{a m}($ Out $)$

- if $\Delta<\tilde{\Delta}(n): \alpha_{C R}^{b m}($ Out $)>\alpha_{C R}^{a m}($ Out $)>\alpha_{C R}^{b m}($ Ins $)$

The comparison of $\alpha_{C R}^{a m}($ Ins $)$ and $\alpha_{C R}^{b m}(O u t)$ is not useful, only the border lines which are the lowest down are restricting. If we take into account all the firms in the industry, then, for the case $\Delta>\tilde{\Delta}(n)$, the merger will reduce the possibility of collusion ex post. But if there is a high degree of asymmetry between firms $(\Delta<\tilde{\Delta}(n))$, the space of parameters under which firms tend to collude increases after the merger takes place. The following graphic summarizes the results:
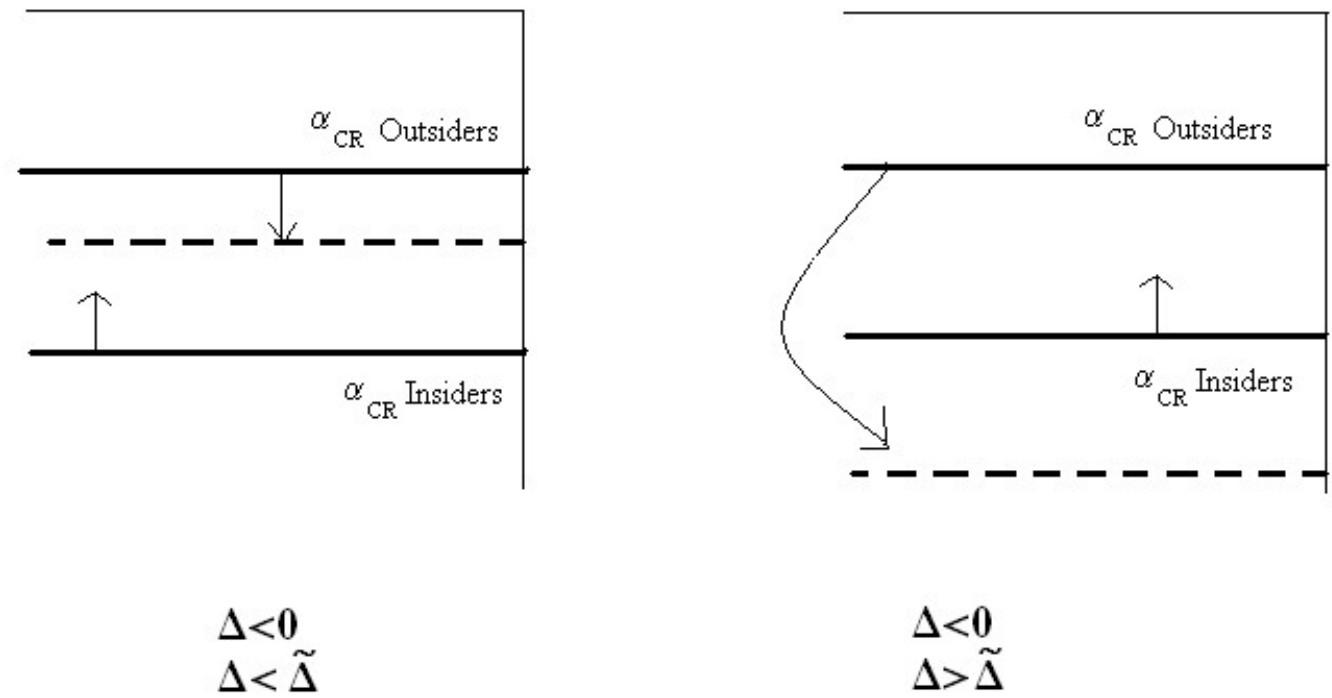

$\Delta<0$

$\Delta>\tilde{\Delta}$

Figure 4: The impact of a merger on $\alpha_{C R}$ in the case: $\Delta<0$

We then obtain the following proposition: 
proposition 3. Given $\tilde{\Delta}(n)(\tilde{\Delta}(n)<0)$ such as : $\alpha_{C R}^{b m}($ Ins $)=\alpha_{C R}^{a m}($ Out $)$. For $\Delta<\tilde{\Delta}(n)$, the merger increases the space of parameters under which firms collude. For $\Delta>\tilde{\Delta}(n)$, the merger reduces the space of parameters under which firms collude.

The main originality of the paper is that we can compute the exact value of asymmetry ex ante in order for the merger to have pro-competitive effects, taking into account the possibility for firms to denounce the cartel agreement (apply for leniency).

The variable $\tilde{\Delta}(n)$, which satisfies the equality: $\alpha_{C R}^{b m}($ Ins $)=\alpha_{C R}^{a m}(O u t)$, is not the parameter which establishes a perfect symmetry of firms ex post. As a matter of fact, the parameter which establishes an ex post perfect symmetry of firms is given by:

$$
\bar{\Delta}(n)=-\frac{(n-2)}{2(n-1)}
$$

Proof. See the appendix G.

Moreover, we prove that: $\bar{\Delta}(n)<\tilde{\Delta}(n)$

Proof. See the appendix H.

The following graphic summarizes the effect of a merger, depending of the degree of asymmetry between firms. 


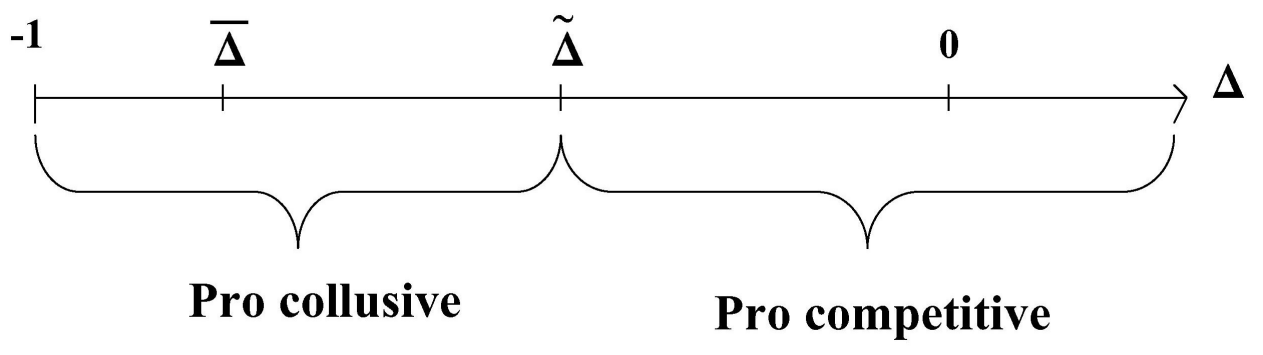

Figure 5: Summary diagram

Below $\tilde{\Delta}(n)$, a merger increases the possibilities for firms to collude whereas above, the merger has pro-competitive effects. Moreover, the parameter which establishes a perfect symmetry of firms ex post $(\bar{\Delta}(n))$ is always smaller than $\tilde{\Delta}(n)$. This finds the usual results of the literature about the impact of mergers on collusion, and we reinforce them by computing the value of ex ante asymmetry necessary to decrease the space of parameters under which firms tend to collude ex post.

\section{Comparative statics analysis on the other border lines}

\section{1. $\mathrm{NC}$ versus $\mathrm{CNR}$}

In this section, we make comparative statics on the border line $\alpha_{N C}$ before and after merger. The parameters $\delta$ and $s$ are assumed to be constant (they do not have any impact of the moving of the border line $\alpha_{N C}$ ) and consequently, the only difference considering the sign of $\alpha_{C R}^{b m}-\alpha_{C R}^{a m}$ and $\alpha_{N C}^{b m}-\alpha_{N C}^{a m}$ is that in one case we consider reduced fine ( $f$ is assumed to be equal to 0 ), whereas in the other case, we consider the full fine $F$.

The previous propositions 1 and 2 remain valid considering $\alpha_{N C}$. 
For the proposition 3, the only difference is the value of the threshold $\Delta(n)$ for which the merger has procompetitive effects. We obtain the following proposition.

proposition 4. Given $\hat{\Delta}(\hat{\Delta}<0)$ such as : $\alpha_{N C}^{b m}($ Ins $)=\alpha_{N C}^{a m}($ Out $)$. For $\Delta<\hat{\Delta}$, the merger increases the space of parameters under which firms collude without revelation. For $\Delta>\hat{\Delta}$, the merger reduces the space of parameters under which firms collude without revelation.

Proof. The values of $\hat{\Delta}(n)$ are reported in the appendix I.

These results reinforce our previous results obtained for the border line $\alpha_{C R}$.

\section{CR versus CNR}

Comparative statics results on $s_{C N R}$ allow to know the impact of a merger on the effectiveness of leniency.

Firstly, we suppose that firms are ex ante symmetric. Then we obtain the following proposition :

proposition 5. If each firm has initially the same production capacity, then a merger will increase (resp. decrease) the space of parameters under which firms tend to collude without revelation for the insiders (resp. the outsiders). The merger will then reduce the space of parameters under which firms tend to collude without revelation in the industry.

Proof. See Appendix J.

If we consider ex ante asymmetric firms, we prove that, as previously, there exists a threshold under which a merger has procollusive effects in 
the sense that under collusion, a merger decreases the incentives for firms to reveal the information to the antitrust authority and so to apply for leniency.

We then obtain the following proposition :

proposition 6. Given $\check{\Delta}(\check{\Delta}<0)$ such as : $s_{C N R}^{b m}($ Ins $)=s_{C N R}^{a m}($ Out $)$. For $\Delta<\check{\Delta}$, the merger reduces the incentives for colluding firms to apply for leniency. For $\Delta>\check{\Delta}$, the merger increases the incentives for colluding firms to apply for leniency.

Proof. The values of $\check{\Delta}(n)$ are reported in the appendix K.

\section{Concluding remarks}

This paper deals with the impact of a merger on the possibility for firms to collude. The major contribution of this article is to consider an ex ante merger control associated with an ex post detection of explicit collusion, allowing for leniency. Our results confirm the results obtained by several authors dealing with this subject (Compte, Jenny and Rey (2002), Vasconcelos $(2005), \ldots)$ and we reinforce these by computing the optimal threshold of asymmetry among insiders and outsiders such as a merger has procompetitive effects.

Of course, antitrust authority does not evaluate only pro-collusive effect but also the possibility of abuse of dominant position and then faces a tradeoff between decreasing the risk of pro-collusive effects (when two efficient firms merge for example) and increasing the market power of merged entity. 


\section{Appendix}

\section{Appendix A : Justification of $n>3$}

For $n \leq 2$, then a merger reduces the competition to only one firm, which is not an interesting case to study.

For $n=3$, we can easily prove that, in the case of symmetric firms before merger $\left(k_{i}=1 / 3\right)$, then the post-merger profit of an outsider is less in the case of collusive equilibrium than in a case of Nash equilibrium ${ }^{12}$. Also, the discount factor under which collusion is sustainable for the outsider is higher than 1 , there is never collusion after merger, which is not an interesting case to study also.

\section{Appendix B : Profit functions}

- Nash profit.

The individual maximization program when firms play non cooperatively is:

$\operatorname{Max}_{q_{i}}\left(1-\left(\sum_{i=1}^{n} q_{i}\right)\right) q_{i}-\frac{q_{i}^{2}}{2 k_{i}}$

Then, equilibrium values are :

$Q=\frac{\beta}{(1+\beta)}$

$p=\frac{1}{1+\beta}$

$q_{i}=\frac{\beta_{i}}{1+\beta}$

with $\beta_{i}=\frac{k_{i}}{k_{i}+1}$ and $\beta=\sum_{i=1}^{n}\left(\beta_{i}\right)$ (Cf McAfee and Williams, 1992).

- Collusion profit.

\footnotetext{
${ }^{12}$ Profit functions are reported in Appendix B
} 
As Vasconcelos (2005), we suppose that the collusive outcomes are based on an allocation of the monopoly output proportional to the individual capital stocks. This is the profit maximizing allocation of a monopolist with decreasing returns.

The maximization program when firms play cooperatively is:

$\operatorname{Max}_{Q^{M}}\left(1-Q^{M}\right) Q^{M}-\frac{\left(Q^{M}\right)^{2}}{2 \sum k_{i}}$

with $\sum_{i=1}^{n} k_{i}=1$

We obtain:

$Q^{M}=\frac{1}{3}$ and

$q^{M}=k_{i} * \frac{1}{3}$ and we replace $Q^{M}$ and $q^{M}$ in the profit function to obtain the equilibrium collusion profit.

\section{- Deviation profit.}

As in Rothschild (1999), we suppose here that deviation takes the form which is conventionally assumed in models of this type : the deviant takes the allocated cartel outputs of all other firms as given and selects the output which maximizes its own profits.

The maximization program for a firm which deviates from the collusive agreement is:

$\operatorname{Max}_{q_{i}}\left(1-q_{i}-\left(1-k_{i}\right)\left(\frac{1}{3}\right)\right) * q_{i}-\frac{q_{i}^{2}}{2 k_{i}}$

$q_{i}^{D}=\frac{1-\left(1-k_{i}\right)\left(\frac{1}{3}\right)}{2+k_{i}^{-1}}$ and we replace in the profit function to obtain the deviation profit. 


\section{Appendix C : Proof of lemma 2}

In order to compute the value of $\phi$, we have to compute the values of $\alpha_{C R}$ before and after the merger.

$$
\alpha_{C R}=\frac{\pi_{M}-(1-\delta) \pi_{D}-\delta \pi_{N}}{\left(\pi_{M}-\pi_{N}\right)}
$$

Profits functions ${ }^{13}$ for the insiders before and after merger (with $k_{i}=\frac{1}{n}$ ) are given by:

$$
\begin{gathered}
\pi_{M}=\frac{1}{6} k_{i} \\
\Rightarrow \pi_{M}^{b m}=\frac{1}{6 n}, \pi_{M}^{a m}=\frac{1}{6 n} \\
\pi_{D}=\frac{k_{i}\left(-2-k_{i}\right)^{2}}{18\left(1+2 k_{i}\right)} \\
\Rightarrow \pi_{D}^{b m}=\frac{(2 n+1)^{2}}{18 n^{2}(n+2)}, \pi_{D}^{a m}=\frac{2(n+1)^{2}}{9 n^{2}(n+4)} \\
\beta=\sum_{i=1}^{n}\left(\beta_{i}\right)=\sum_{i=1}^{n}\left(\frac{b k_{i}}{b k_{i}+1}\right) \\
\beta^{a m}=\frac{2 k_{i}}{k_{i}+1}+\frac{(n-2)\left(1-2 k_{i}\right)}{1-2 k_{i}+n-2}=\frac{n}{1+n} \\
\frac{2 k_{i}}{2 k_{i}+1}+\frac{(n-2)\left(1-2 k_{i}\right)}{1-2 k_{i}+n-2}=1-\frac{3}{n+1}+\frac{2}{n+2} \\
\pi_{N}^{b m}=\frac{n+2}{2(2 n+1)^{2}}, \pi_{N}^{a m}=\frac{(n+1)^{2}(4+n)}{2 n^{2}(5+2 n)^{2}} \\
\pi_{N}=\frac{\beta_{i}\left(2 k_{i}-\beta_{i}\right)}{2 k_{i}(1+\beta)^{2}} \\
\end{gathered}
$$

\footnotetext{
${ }^{13}$ We compute the individual profit function after merger.
} 
We then replace these expressions in $\alpha_{C R}^{b m}$ and $\alpha_{C R}^{a m}$ in order to compute the value of: $\alpha_{C R}^{b m}-\alpha_{C R}^{a m}$ for the insiders. We obtain:

$$
\phi^{\text {Ins }}=\frac{2(12+n(109+8 n(17+n(7+n))))(-1+\delta)}{3 n(2+n)(4+n)(6+n(4+n))}
$$

It is straightforward to prove that $\phi^{\text {Ins }}<0$.

Now we have to compute the value of $\phi$ for the outsiders.

Premerger profit are the same for insiders and outsiders because firms are perfectly symmetric. Post-merger profits are given by:

$\pi_{M}^{a m}=\frac{1}{6 n}, \pi_{D}^{a m}=\frac{2(n+1)^{2}}{9 n^{2}(n+4)}, \beta^{a m}=1-\frac{3}{n+1}+\frac{2}{n+2}, \pi_{N}^{a m}=\frac{(n+2)^{3}}{2 n^{2}(5+2 n)^{2}}$

We infer that:

$$
\phi^{\text {Out }}=\frac{-4(1+n(5+2 n))(-1+\delta)}{n(3+n)(-8+(-1+n) n)}
$$

$\phi^{\text {Out }}$ is strictly positive (by assumptions $n>3$ ).

\section{Appendix D : Domain of definition of $\Delta$}

When we consider a relative efficiency of insiders $(\Delta>0)$, the sum of production capacities of insiders can not exceed 1, then:

$$
2\left(\frac{1+\Delta}{n}\right)<1
$$

and $\Delta<\frac{n}{2}-1$.

For the opposite case $(\Delta<0)$, the production capacity of a merged firm must be greater than 0 , then:

$$
\frac{1+\Delta}{n}>0
$$

and $\Delta>-1$. 


\section{Appendix E : Proof of lemma 3}

After simplifications, we obtain :

$$
\begin{gathered}
\alpha_{C R}^{b m}(\text { Ins })=\frac{\frac{3}{n}+\frac{(-1+\delta)(1+2 n+\Delta)^{2}}{n^{2}(2+n+2 \Delta)}-\frac{9 \delta(2+n+2 \Delta)\left(2+n-n^{2}+2 \Delta\right)^{2}}{\left(-2 n^{3}+n^{2}(1-2 \Delta)+2(1+\Delta)^{2}+n(1+\Delta)(5+2 \Delta)\right)^{2}}}{3\left(\frac{1}{n}-\frac{3(2+n+2 \Delta)\left(2+n-n^{2}+2 \Delta\right)^{2}}{\left(-2 n^{3}+n^{2}(1-2 \Delta)+2(1+\Delta)^{2}+n(1+\Delta)(5+2 \Delta)\right)^{2}}\right)} \\
\alpha_{C R}^{a m}(\text { Ins })=\frac{3 n+\frac{4(-1+\delta)(1+n+\Delta)^{2}}{4+n+4 \Delta}-\frac{9 \delta\left(2+n-n^{2}+2 \Delta\right)^{2}(4+n+4 \Delta)}{\left(n+2 n^{2}+4 n \Delta-2(1+\Delta)(5+2 \Delta)\right)^{2}}}{3\left(n-\frac{3\left(2+n-n^{2}+2 \Delta\right)^{2}(4+n+4 \Delta)}{\left(n+2 n^{2}+4 n \Delta-2(1+\Delta)(5+2 \Delta)\right)^{2}}\right)}
\end{gathered}
$$

We compute the value of $\alpha_{C R}^{b m}($ Ins $)-\alpha_{C R}^{a m}($ Ins $)$. To sign this difference depending on $n, \delta$ and $\Delta$, we plot (in three dimensions) this function varying $n$ and we obtain that this difference is always negative $\forall n>3, \forall \Delta \in]-1, \frac{n}{2}-$ $1[$.

For the outsiders, we obtain:

$$
\begin{aligned}
\alpha_{C R}^{b m}(\text { Out }) & =\frac{\frac{3\left(1-\frac{2 \Delta}{-2+n}\right)}{n}+\frac{(-1+\delta)\left(2+3 n-2 n^{2}+2 \Delta\right)^{2}(n-2(1+\Delta))}{(-2+n)^{2} n^{2}\left(n^{2}-4(1+\Delta)\right)}-\frac{9 \delta(1+n+\Delta)^{2}\left(n^{2}-4(1+\Delta)\right)(n-2(1+\Delta))}{\left(2 n^{3}-2(1+\Delta)^{2}+n^{2}(-1+2 \Delta)-n(1+\Delta)(5+2 \Delta)\right)^{2}}}{3\left(\frac{1-\frac{2 \Delta}{-2+n}}{n}-\frac{3(1+n+\Delta)^{2}\left(n^{2}-4(1+\Delta)\right)(n-2(1+\Delta))}{\left(2 n^{3}-2(1+\Delta)^{2}+n^{2}(-1+2 \Delta)-n(1+\Delta)(5+2 \Delta)\right)^{2}}\right)} \\
\alpha_{C R}^{a m}(\text { Out }) & =\frac{3 n\left(1-\frac{2 \Delta}{-2+n}\right)+\frac{(-1+\delta)\left(2+3 n-2 n^{2}+2 \Delta\right)^{2}(n-2(1+\Delta))}{(-2+n)^{2}\left(n^{2}-4(1+\Delta)\right)}-\frac{9 \delta(2+n+2 \Delta)^{2}\left(n^{2}-4(1+\Delta)\right)(n-2(1+\Delta))}{\left(n+2 n^{2}+4 n \Delta-2(1+\Delta)(5+2 \Delta)\right)^{2}}}{3\left(n-\frac{2 n \Delta}{-2+n}-\frac{3(2+n+2 \Delta)^{2}\left(n^{2}-4(1+\Delta)\right)(n-2(1+\Delta))}{\left(n+2 n^{2}+4 n \Delta-2(1+\Delta)(5+2 \Delta)\right)^{2}}\right)}
\end{aligned}
$$

We prove that: $\left.\alpha_{C R}^{b m}-\alpha_{C R}^{a m}>0, \forall n>3, \forall \Delta \in\right]-1, \frac{n}{2}-1[$.

\section{Appendix F : Proof of lemma 5}

We obtain that $\alpha_{C R}^{b m}($ Ins $)-\alpha_{C R}^{a m}($ Out $)>0$ for $\Delta>\tilde{\Delta}(n)$.

$$
\begin{gathered}
\alpha_{C R}^{b m}(\text { Ins })-\alpha_{C R}^{a m}(\text { Out })=\frac{\frac{3}{n}+\frac{(-1+\delta)(1+2 n+\Delta)^{2}}{n^{2}(2+n+2 \Delta)}-\frac{9 \delta(2+n+2 \Delta)\left(2+n-n^{2}+2 \Delta\right)^{2}}{\left(-2 n^{3}+n^{2}(1-2 \Delta)+2(1+\Delta)^{2}+n(1+\Delta)(5+2 \Delta)\right)^{2}}}{3\left(\frac{1}{n}-\frac{3(2+n+2 \Delta)\left(2+n-n^{2}+2 \Delta\right)^{2}}{\left(-2 n^{3}+n^{2}(1-2 \Delta)+2(1+\Delta)^{2}+n(1+\Delta)(5+2 \Delta)\right)^{2}}\right)}- \\
-\frac{-\left(3 n\left(1-\frac{2 \Delta}{-2+n}\right)+\frac{(-1+\delta)\left(2+3 n-2 n^{2}+2 \Delta\right)^{2}(n-2(1+\Delta))}{(-2+n)^{2}\left(n^{2}-4(1+\Delta)\right)}-\frac{9 \delta(2+n+2 \Delta)^{2}\left(n^{2}-4(1+\Delta)\right)(n-2(1+\Delta))}{\left(n+2 n^{2}+4 n \Delta-2(1+\Delta)(5+2 \Delta)\right)^{2}}\right)}{3\left(n-\frac{2 n \Delta}{-2+n}-\frac{3(2+n+2 \Delta)^{2}\left(n^{2}-4(1+\Delta)\right)(n-2(1+\Delta))}{\left(n+2 n^{2}+4 n \Delta-2(1+\Delta)(5+2 \Delta)\right)^{2}}\right)}
\end{gathered}
$$


The derivative of this expression function of $\delta$ does not depend of $\delta$ and so we can fix $\delta=0.9$ for example because $\delta$ does not affect the values of $\tilde{\Delta}(n)$.

The values of $\tilde{\Delta}(n)$ are given by resolving: $\frac{\alpha_{C R}^{b m}(\text { Ins })}{\alpha_{C R}^{a m}(\text { Out })}=1$.

We then obtain:

\begin{tabular}{|l|l|}
\hline$n$ & $\tilde{\Delta}(n)$ \\
4 & -0.180177 \\
5 & -0.163638 \\
6 & -0.148173 \\
7 & -0.134942 \\
8 & -0.123741 \\
9 & -0.114209 \\
10 & -0.106025 \\
$\cdots$ & $\cdots$ \\
\hline
\end{tabular}

Table 1: Values of $\tilde{\Delta}(n)$.

\section{Appendix $\mathbf{G}:$ Values of $\bar{\Delta}(n)$}

In order to establish perfect symmetry ex post, $\bar{\Delta}(n)$ must satisfy: $2\left(\frac{1+\bar{\Delta}(n)}{n}\right)=$ $\frac{1-\left(\frac{2 \bar{\Delta}(n)}{n-2}\right)}{n}$.

Appendix H : Proof of: $\bar{\Delta}(n)<\tilde{\Delta}(n)$

We compute the value of $\bar{\Delta}(n)$ for each value of $n$ : 


\begin{tabular}{|l|l|}
\hline$n$ & $\bar{\Delta}(n)$ \\
4 & $-\frac{1}{3}$ \\
5 & $-\frac{3}{8}$ \\
6 & $-\frac{2}{5}$ \\
7 & $-\frac{5}{12}$ \\
8 & $-\frac{3}{7}$ \\
9 & $-\frac{7}{16}$ \\
10 & $-\frac{4}{9}$ \\
\hline
\end{tabular}

Table 2: Values of $\bar{\Delta}(n)$.

By making a comparison between the two previous tables, we infer that : $\bar{\Delta}(n)<\tilde{\Delta}(n), \forall n$

\section{Appendix I : values of $\hat{\Delta}(n)$.}

The only difference computing the values of $\hat{\Delta}(n)$ or $\tilde{\Delta}(n)$ is that in only one case, we consider the amount of the fine. By numerical simulations we can prove that $\hat{\Delta}(n)$ is a increasing function of the full fine $F$. The following table gives the values of $\hat{\Delta}(n)$ for $F=0.01$.

\begin{tabular}{|l|l|}
\hline$n$ & $\hat{\Delta}(n)$ \\
4 & -0.179602 \\
5 & -0.145101 \\
6 & -0.116431 \\
7 & -0.0944429 \\
8 & -0.0776809 \\
9 & -0.064774 \\
10 & -0.0546968 \\
$\cdots$ & $\cdots$ \\
\hline
\end{tabular}

Table 3: Values of $\hat{\Delta}(n)$. 


\section{Appendix J : Proof of proposition 5}

For the insiders :

$$
\begin{aligned}
s_{C N R}^{b m} & =\frac{(-1+n)^{2}}{1+n\left(-2+n+6 F(1+2 n)^{2}\right)} \\
s_{C N R}^{a m} & =\frac{(-2+n)(6+n(4+n))}{-12+n\left(-2+n\left(2+n+6 F(5+2 n)^{2}\right)\right)}
\end{aligned}
$$

Consequently,

$$
s_{C N R}^{b m}-s_{C N R}^{a m}=\frac{-18 F n(-4+n(-25+4(-2+n) n))}{\left(1+n\left(-2+n+6 F(1+2 n)^{2}\right)\right)\left(-12+n\left(-2+n\left(2+n+6 F(5+2 n)^{2}\right)\right)\right)}
$$

It is straightforward to prove that this expression is strictly negative.

For the outsiders :

$s_{C N R}^{b m}$ is the same than for insiders.

$s_{C N R}^{a m}=\frac{(3+n)(-8+(-1+n) n)}{-24+n\left(-11+n\left(2+n+6 F(5+2 n)^{2}\right)\right)}$

Consequently,

$$
s_{C N R}^{b m}-s_{C N R}^{a m}=\frac{72 F n(2+n)(1+n(5+2 n))}{\left(1+n\left(-2+n+6 F(1+2 n)^{2}\right)\right)\left(-24+n\left(-11+n\left(2+n+6 F(5+2 n)^{2}\right)\right)\right)}
$$

It is sraightforward to prove that this expression is strictly positive.

\section{Appendix K : Values of $\check{\Delta}(n)$.}

We obtain that $s_{C N R}^{b m}($ Ins $)-s_{C N R}^{a m}($ Out $)>0$ for $\Delta>\check{\Delta}(n)$.

$$
\begin{aligned}
& s_{C N R}^{b m}(\text { Ins })-s_{C N R}^{a m}(\text { Out })=\frac{(1+\Delta)\left(\frac{1}{n}-\frac{3(2+n+2 \Delta)\left(2+n-n^{2}+2 \Delta\right)^{2}}{\left(-2 n^{3}+n^{2}(1-2 \Delta)+2(1+\Delta)^{2}+n(1+\Delta)(5+2 \Delta)\right)^{2}}\right)}{6\left(F+\frac{1+\Delta}{6 n}-\frac{(1+\Delta)(2+n+2 \Delta)\left(2+n-n^{2}+2 \Delta\right)^{2}}{2\left(-2 n^{3}+n^{2}(1-2 \Delta)+2(1+\Delta)^{2}+n(1+\Delta)(5+2 \Delta)\right)^{2}}\right)}- \\
& \frac{n-\frac{2 n \Delta}{-2+n}-\frac{3(2+n+2 \Delta)^{2}\left(n^{2}-4(1+\Delta)\right)(n-2(1+\Delta))}{\left(n+2 n^{2}+4 n \Delta-2(1+\Delta)(5+2 \Delta)\right)^{2}}}{6 n^{2}\left(F+\frac{1-\frac{2 \Delta}{-2+n}}{6 n}-\frac{(2+n+2 \Delta)^{2}\left(n^{2}-4(1+\Delta)\right)(n-2(1+\Delta))}{2 n^{2}\left(n+2 n^{2}+4 n \Delta-2(1+\Delta)(5+2 \Delta)\right)^{2}}\right)}
\end{aligned}
$$

The values of $\check{\Delta}(n)$ are given by resolving: $s_{C N R}^{b m}($ Ins $)-s_{C N R}^{a m}($ Out $)=0$ for each value of $n$. After having set values for $n$, we can prove that $F$ has no 
impact of the value of $\breve{\Delta}(n)$, and we obtain the following table (for every value of $F>0)$ :

\begin{tabular}{|l|l|}
\hline$n$ & $\check{\Delta}(n)$ \\
4 & -0.179445 \\
5 & -0.1412 \\
6 & -0.110969 \\
7 & -0.0885561 \\
8 & -0.0718996 \\
9 & -0.0593288 \\
10 & -0.049672 \\
$\cdots$ & $\ldots$ \\
\hline
\end{tabular}

Table 4: Values of $\check{\Delta}(n)$. 


\section{References}

Cabral, L., 2000. Introduction to industrial organization. MIT Press, Cambridge, MA.

Compte, O., Jenny, F., Rey, P., 2002. Capacity constraints, mergers and collusion. European Economic Review 46, 1-29.

Friedman, J.W., 1971. A non-cooperative equilibrium for supergames. Review of Economic Studies 28, 1-12.

McAfee, P., Williams, M., 1992. Horizontal mergers and antitrust policy. Journal of Industrial Economics 40, 181-187.

Motta, M., Polo, M., 2003. Leniency programs and cartel prosecution. International Journal of Industrial Organization 21, 347-379.

Penard, T., 1997. Choix de capacités et comportements stratégiques : une approche par la théorie des jeux répétés. Annales d'Économie et de Statistique 46, 203-224.

Perry, M., Porter, R., 1985. Oligopoly and the incentive for horizontal merger. American Economic Review 75, 219-227.

Rothschild, R., 1999. Cartel stability when costs are heterogeneous. International Journal of Industrial Organization 17, 717-734.

Vasconcelos, H., 2005. Tacit collusion, cost asymmetries, and mergers. The Rand Journal of Economics 36, 39-62. 